\title{
IMPACT OF CINNAMON AND CLOVES EXTRACTS INCORPORATED IN FLUORIDE VARNISH CONTAINING CPP-ACP ON MICROHARDNESS AND COLOR OF ENAMEL
}

\author{
Rehab Khalil Safy* and Hanaa Elgamily**
}

\begin{abstract}
Objective: The current study aimed to evaluate the effects of methanolic extracts of Cinnamon and Cloves mixed with Fluoride Varnish Containing CPP-ACP (MI Varnish ${ }^{\mathrm{TM}}$ ) treatments on the enamel microhardness and color. Material and Methods: Forty enamel specimens obtained from twenty human impacted third molars were randomly divided into four groups $(n=10)$ according to surface treatment: (G1) MI Varnish ${ }^{\mathrm{TM}}$ mixed with methanolic extract of Cinnamon; (G2) MI Varnish $^{\mathrm{TM}}$ mixed with methanolic extract of Cloves; (G3) MI Varnish ${ }^{\mathrm{TM}}$ mixed with methanolic extracts of Cinnamon and Cloves meanwhile (G4) MI Varnish ${ }^{\mathrm{TM}}$ alone. Specimens were subjected to $\mathrm{pH}$ cycling. Color $(\Delta \mathrm{E})$ and surface microhardness were measured for each specimen at base line, after demineralization and post treatment. Results: The highest microhardness values presented in MI Varnish alone $(\mathrm{G} 4)$ and MI Varnish ${ }^{\mathrm{TM}}$ mixed with methanolic extracts of Cinnamon and Cloves (G3) without any significant difference between them, followed by MI Varnish ${ }^{\mathrm{TM}}$ mixed with methanolic extract of Cinnamon (G1), while the lowest hardness values were found in MI Varnish $^{\mathrm{TM}}$ mixed with methanolic extract of Cloves (G2). There was an increase in $\triangle \mathrm{E} 3$ values for all groups. Conclusions: Under the limitations of the current study, application of Cinnamon and Clove as herbal antibacterial medicaments does not affect enamel microhardness negatively when added with the MI paste at certain ratio. Meanwhile, unacceptable color changes of enamel surface are expected.
\end{abstract}

Key words: Cinnamon, Cloves, enamel, microhardness, color.

\section{INTRODUCTION}

Dental caries is considered one of the most prevalent infections of all oral lesions. ${ }^{[1]}$ Demineralization of the hard tissues via acid generated by cariogenic bacteria is the fundamental mechanism of caries. Streptococcus mutans is the most well-known cariogenic bacteria related with dental caries. It is accepted to assume a fundamental function in the pathogenesis of dental caries. It is engaged with caries initiation, while, Lactobacillus distinctively cause progress of existing carious lesions. ${ }^{[2]}$ Since there is a strong relationship

* Operative Dentistry Department, Faculty of Dentistry, Suez Canal University, Ismailia, Egypt

** Restorative and Dental Materials Department, Oral and Dental research Division, National Research Centre, Giza, Egypt. 
between dental caries and cariogenic bacteria, numerous efforts have been made to introduce antibacterial agents to eliminate or decrease the number of the cariogenic bacteria in the oral cavity.

It's common knowledge that chemicals such as fluoride, chlorhexidine and antibiotics which were utilized to counteract dental caries for a very long while, were related with some drawbacks such as fluorosis, discoloration of teeth and restorations, unpleasant taste, tongue discoloration, desquamation of the oral mucosa and the increased bacterial resistance to antibiotics. ${ }^{[3,4,5]}$ Therefore, till now there is no ideal antibacterial agent to prevent dental caries. These issues require persistent research for alternative antibacterial treatments with limited or even no drawbacks, for example plants. Utilizing of natural antimicrobial agents is viewed as fruitful procedures for the revelation of new medications. They have been utilized for a large number of years in folk medicine as they proved to be safe and specific for oral bacteria. ${ }^{[3-6,7,8]} \mathrm{In}$ in-vitro studies, extracts of Cinnamon and Cloves showed excellent antibacterial activity on the growth of $S$. mutans and some other oral pathogens. ${ }^{[9,10]}$

Considering all above claims and facts, Cinnamon and Clove extracts would be promising substances for development of antibacterial agents against $S$. mutans and L. acidophilus. Beside the role of the natural antibacterial agents for preventing dental carries, increasing the teeth resistance to acid is one of the fundamental factors in caries prevention through encouraging the advancement of enamel surface remineralization. ${ }^{[11]}$ More advanced fluoride varnish containing casein phosphopeptide-amorphous calcium phosphate (CPP-ACP) was developed recently. ${ }^{[12]}$ The CPP$\mathrm{ACP}$ has the ability to control the free calcium and phosphate ion activity, providing a state of super saturation that enhance enamel remineralization. ${ }^{[12-15]}$ For augmenting the antibacterial activity, extracts of both Cinnamon and Cloves were added to the enamel surface in addition to the CPP-ACP that could produce higher antibacterial activity than when the CPP-ACP is used alone. ${ }^{[9,10]}$

Thinking about these results and realities, assessment of the effects of both Cinnamon and Cloves on the remineralizing efficiency of CPPACP was compulsory. Also, as the interest in color research in dentistry has expanded essentially over the recent decades, their effect on enamel color should be evaluated. Accordingly, the current study was carried out to evaluate the impact of Cinnamon and Cloves on the remineralizing effect of CPP$\mathrm{ACP}$ and enamel color in comparison to the results of CPP-ACP varnish alone.

\section{MATERIAL AND METHODS}

Twenty humans impacted third molars recently extracted from patients in the age extend 20-30 years were assembled, cleaned and secured in distilled water containing $0.2 \%$ thymol antiseptic solution for one month at $4{ }^{\circ} \mathrm{C}$ till testing. ${ }^{[16]}$ Only sound teeth without having any enamel defects were involved. The roots of all the selected teeth were cut around $1 \mathrm{~mm}$ beneath the CEJ. At that point, the coronal part of each tooth was separated mesiodistally into 2 parts to deliver 40 enamel specimens from buccal and lingual surfaces of $(8 \mathrm{~mm} \times 4 \mathrm{~mm} \times 3 \mathrm{~mm})$.

All enamel specimens were free of any imperfections, like cracks or pores. The specimens were mounted in plastic molds with chemically cured acrylic resin, with the enamel surface confronting upward, allowed to set to make enamel blocks and then specimens were labeled for easy identification of each group. A $6 \mathrm{~mm}^{2}$ zone was demarcated with a sticky tape on each specimen, and two layers of nail polish were utilized to cover all around the tape. At that point, the sticky tape was expelled to expose the experimental area. Specimens were distinguished by marking numbers on its bottom and kept in distilled water for 24 hours. 


\section{Baseline Knoop Microhardness measurements}

The baseline microhardness estimations were taken at three distinct points on the dentin specimens. The indentations were made around 0.5 $\mathrm{mm}$ from the interface and $1 \mathrm{~mm}$ separated from each other. ${ }^{[17]}$ Each estimation was finished using a $100 \mathrm{~g}$ load for $10 \mathrm{Sec}$ applied perpendicularly to the enamel surface. The values were averaged to produce one hardness value for each specimen. The microhardness estimations were performed utilizing a Vickers Microhardness Tester (Wilson miniaturized scale hardness analyzer, display Tukon 1102, Germany) with a Vickers diamond indenter and a 20X lens. Micro-hardness measurements were acquired utilizing the accompanying equation: $\mathrm{HV}=1.854 \mathrm{P} / \mathrm{d} 2$ Where, $\mathrm{HV}$ is Vickers hardness in $\mathrm{Kgf} / \mathrm{mm}^{2}, \mathrm{P}$ is the load in $\mathrm{Kgf}$ and $\mathrm{d}$ is the average diagonals length in $\mathrm{mm}$.

\section{Baseline color measurements:}

A reflection spectrophotometer (UVPC Shimadzu 3101PC, Germany) was utilized to gauge the shade changes. The CIE L*a*b* color framework is a three dimensional uniform color space with axis $L^{*}, a^{*}$, and $b^{*}$ where the difference from the starting point measures the color change. The $\mathrm{L}^{*}$ values symbolize lightness. Both $\mathrm{a}^{*}$ and $b^{*}$ values symbolize the redness to greenness and yellowness to blueness axes, respectively. Three readings of $\mathrm{L}^{*}, \mathrm{a}^{*}$ and $\mathrm{b}^{*}$ were measured for each specimen, and the mean was calculated.

\section{Artificial carious lesion preparation}

Carious lesions were artificially made by storing of all enamel specimens in a demineralizing medium for two days. The demineralizing solution comprised of $2.2 \mathrm{mM} \mathrm{Ca}^{+2}, 2.2 \mathrm{mM} \mathrm{PO}^{-3}$, and 50 $\mathrm{mM}$ acetic acid at a $\mathrm{pH}$ of 4.4. These demineralizing solutions were changed each $12 \mathrm{hrs}$. After two days, the teeth were expelled from the demineralizing solution. ${ }^{[18]}$ Then color and Knoop Microhardness measurements were accomplished for all the demineralized specimens. A spread sheet for randomization produced with Microsoft Excel (Microsoft Corporation, Redmond, USA) was utilized to haphazardly partition the demineralized enamel blocks into four groups $(\mathrm{n}=10)$ as indicated by the randomized complete block design.

After randomized distribution of enamel specimens among groups they were treated as the following: (G1) 0.5ml MI Paste (10\% CPP-ACPF; GC MI Paste Plus, Ultradent Products Inc.) mixed with $0.5 \mathrm{ml}$ methanolic extract of Cinammon; (G2) $0.5 \mathrm{ml}$ MI Paste mixed with $0.5 \mathrm{ml}$ methanolic extract of Cloves; (G3) $0.5 \mathrm{ml}$ MI Paste mixed with $0.25 \mathrm{ml}$ methanolic extract of Cinammon and with $0.25 \mathrm{ml}$ methanolic extract of Cloves meanwhile (G4) $0.5 \mathrm{ml}$ MI Paste only. In all the specimens the paste, Cinammon and Clove were applied with a micro brush on their enamel surfaces.

\section{pH cycling}

$\mathrm{pH}$ cycling was performed to simulate the cariogenic challenge in conjunction with the treatments. Standardized $\mathrm{pH}$ cycling protocol was utilized as a part of an everyday regime of three cycles, each one of $30 \mathrm{~min}$ of demineralization and $2.5 \mathrm{~h}$ of remineralization, followed by $6 \mathrm{~h}$ in artificial saliva. ${ }^{[19]}$ Before each cycle, the specimens were completely flushed with distilled water. The remineralizing solution consisted of $1.5 \mathrm{mM}$ $\mathrm{CaCl} 2,0.9 \mathrm{mM} \mathrm{KH} 2 \mathrm{PO} 4,130 \mathrm{mM} \mathrm{KCl}$, and 20mM HEPES ( $\mathrm{pH} 7$ ), meanwhile the demineralizing solution $1.5 \mathrm{mM} \mathrm{CaCl} 2,0.9 \mathrm{mM} \mathrm{KH} 2 \mathrm{PO} 4$, and $50 \mathrm{mM}$ acetic acid ( $\mathrm{pH} \mathrm{5)}$. Both of the remineralizing and demineralizing solutions were changed daily. ${ }^{[20]}$

\section{Post treatment knoop Microhardness measurements}

The final indentations were not in the same place as the initial ones and as the markings were moved $100 \mu \mathrm{m}$ far from the past indentations through a digital microscope. 


\section{Post treatment Color measurements:}

Following the $\mathrm{pH}$-cycling/treatment process, the specimens were cleaned in the ultrasonic cleaner for removing any outstanding debris. Later, a last estimation of the three values of $\mathrm{L}^{*}, \mathrm{a}^{*}$ and $\mathrm{b}^{*}$ was done for each specimen. The color change between the base line and final estimation was made by computing the variety of $\Delta \mathrm{L}, \Delta \mathrm{a} \& \Delta \mathrm{b}$. The color change $(\Delta \mathrm{E})$ was calculated where $\Delta \mathrm{E}=\left\{(\Delta \mathrm{L})^{2}+\right.$ $\left.(\Delta \mathrm{a})^{2}+(\Delta \mathrm{b})^{2}\right\}^{1 / 2[21]}$

\section{RESULTS}

\section{Knoop microhardness}

Table 1 shows that the post-treatment microhardness values were significantly lower than baseline microhardness values for G1 (MI paste + Cinnamon extract) and G2 (MI paste + Cloves extract). Meanwhile there were no statistically significant difference between post-treatment and baseline microhardness values of G3 (MI Paste + $0.25 \mathrm{ml}$ Cinnamon extract $+0.25 \mathrm{ml}$ Cloves extract) and G4 (MI Paste). From the analysis of the Knoop microhardness, the final reading (post treatment) significantly differed from Demineralized surface microhardness reading, which presented the highest mean value in (G4) and (G3), followed by (G1), while the lowest hardness values were found in $(G$ 2), as shown in Fig.1.

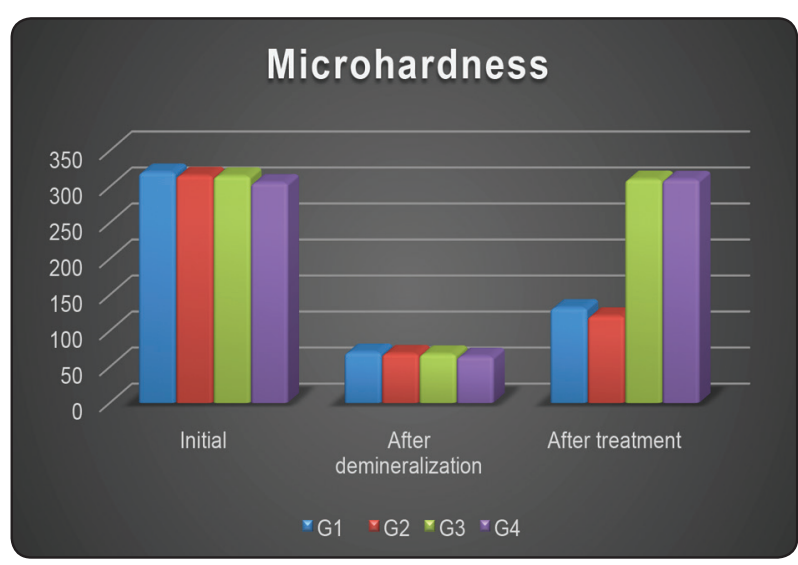

Fig. (1) Bar chart representing microhardness for different groups

\section{Color measurements}

Regarding analyzing the color change values using CIE Lab colorimetric analysis, there was no statistically significant difference between all the groups in $\Delta \mathrm{E} 1$. However, the $\Delta \mathrm{E} 2$ showed the highest mean value in Group 3 followed by Group 2, and Group 4 respectively, meanwhile Group 1 showed the lowest mean value.

By analyzing the $\Delta \mathrm{E} 3$ values, there was an increase in its values for all groups. Where the $\Delta \mathrm{E} 3$ value of Group 3 (MI paste $+0.25 \mathrm{ml}$ Cinnamon $+0.25 \mathrm{ml}$ Cloves extract) recorded the highest mean followed by Group 4 (MI paste) followed by Group 2 (MI paste + Cloves extract) respectively.

TABLE (1): Mean and standard deviation (SD) of Knoop microhardness.

\begin{tabular}{|c|c|c|c|c|c|c|}
\hline \multirow{2}{*}{ Variables } & \multicolumn{2}{|c|}{ Baseline microhardness } & \multicolumn{2}{c|}{$\begin{array}{c}\text { Demineralized surface } \\
\text { microhardness }\end{array}$} & \multicolumn{2}{c|}{$\begin{array}{c}\text { Post treatment } \\
\text { microhardness }\end{array}$} \\
\cline { 2 - 7 } & Mean & SD & Mean & SD & Mean & SD \\
\hline G1 & $320.00^{\mathrm{Aa}}$ & 13.99 & $70.22^{\mathrm{Ca}}$ & 13.18 & $131.84^{\mathrm{Bb}}$ & 48.66 \\
\hline G2 & $315.60^{\mathrm{Aa}}$ & 37.22 & $68.28^{\mathrm{Ca}}$ & 12.22 & $120.46^{\mathrm{Bc}}$ & 30.36 \\
\hline G3 & $314.70^{\mathrm{Aa}}$ & 23.13 & $67.64^{\mathrm{Ba}}$ & 5.93 & $309.20^{\mathrm{Aa}}$ & 55.14 \\
\hline G4 & $305.40^{\mathrm{Aa}}$ & 55.85 & $64.37^{\mathrm{Bb}}$ & 9.10 & $310.90^{\mathrm{Aa}}$ & 60.11 \\
\hline
\end{tabular}

Means followed by different letters uppercase horizontally and lowercase vertically show statistically significant differences (*; significant $(P<0.05)$. 
TABLE (2) The mean values and standard deviation (SD) of color change $(\Delta \mathrm{E})$

\begin{tabular}{|c|c|c|c|c|c|c|c|}
\hline \multirow[t]{3}{*}{ Variables } & \multicolumn{7}{|c|}{ Color change } \\
\hline & \multicolumn{2}{|c|}{$\begin{array}{c}\mathbf{\Delta E 1} \\
\text { differences in color } \\
\text { between baseline \& after } \\
\text { demineralization }\end{array}$} & \multicolumn{2}{|c|}{$\begin{array}{l}\qquad \mathbf{\Delta E 2} \\
\text { differences in color between } \\
\text { after demineralization \& post } \\
\text { treatment }\end{array}$} & \multicolumn{2}{|c|}{$\begin{array}{c}\Delta \mathbf{E} 3 \\
\text { differences in color between } \\
\text { baseline \& post treatment }\end{array}$} & \multirow[t]{2}{*}{ p-value } \\
\hline & Mean & SD & Mean & SD & Mean & SD & \\
\hline Group1 & $2.78^{\mathrm{Ab}}$ & 0.25 & $2.49^{\mathrm{Cb}}$ & 0.25 & $3.91^{\mathrm{Ba}}$ & 0.31 & $<0.001 *$ \\
\hline Group2 & $2.74^{\mathrm{Ab}}$ & 0.22 & $3.41^{\mathrm{Ba}}$ & 0.20 & $4.84^{\mathrm{Aa}}$ & 0.31 & $<0.001 *$ \\
\hline Group3 & $2.96^{\mathrm{Ab}}$ & 0.15 & $4.88^{\mathrm{Aa}}$ & 0.38 & $5.37^{\mathrm{Aa}}$ & 0.32 & $<0.001 *$ \\
\hline Group4 & $2.80^{\mathrm{Ab}}$ & 0.34 & $3.05^{\mathrm{Bb}}$ & 0.26 & $4.92^{\mathrm{Aa}}$ & 0.35 & $<0.001 *$ \\
\hline p-value & \multicolumn{2}{|c|}{$0.524 \mathrm{~ns}$} & \multicolumn{2}{|c|}{$<0.001 *$} & \multicolumn{2}{|c|}{$<0.001 *$} & \\
\hline
\end{tabular}

Means followed by different letters in uppercase vertically and lowercase horizontally indicate significant differences (*; significant $(P<0.05)$.

Meanwhile, samples of the Group 1 represented the lowest man value. Statistical analysis of the $\Delta \mathrm{E} 3$ values showed that there was significant difference between Group 1 and the other groups (Group 2, Group 3 and Group 4).

\section{DISCUSSION}

Prevention of dental caries through increasing enamel resistance to cariogenic acid attack by fluoride and using of chemical antimicrobials are of the most common noninvasive approaches in dentistry. Recently, the use of natural herbs like Cinnamon and Clove as an alternative to conventional treatment in treatment of caries has been introduced. ${ }^{222}$, ${ }^{23]}$ The clove extract consists mainly of phenolic substances which are powerful antioxidants and known to have antimicrobial effect useful for the management of dental caries and periodontal disease. [24] Also, cinnamon resulting in significant decrease in the number of Streptococcus mutans which is one of the most cariogenic pathogen. ${ }^{[25]}$

In the current study, the microhardness of enamel surface was significantly decreased after initiation of carious lesion as an indication of enamel demineralization. After treatment of enamel samples with the selected agents, there was an elevation in the microhardness value. Based on the current analyses, the microhardness results showed that the samples treated by MI paste with Cinnamon extract in Group 1 and MI paste with Clove extract in Group 2 showed increase in microhardness in comparison to the demineralized surface micro but not reaching to the baseline values. The results of the Group 1 are in agreement with Anggono, 2018 who found that Cinnamon with a $\mathrm{pH}$ below the critical $\mathrm{pH}$ of enamel could dissolve the hydroxyapatite crystals creating porous enamel surface, leading to declining of enamel microhardness. ${ }^{[23]}$ Meanwhile, the results of the Group 2 are inconsistent with other previous studies which reporting that presence of Clove extract could elevate the microhardness of demineralized enamel surface that was attributed to their content of calcium and phosphorus ions which are the major components of hydroxyapatite. ${ }^{[22,26]}$ It was assumed that these elements were involved in the outer enamel surface explaining the increase in the values of the microhardness. On contrary, there are many elements other than calcium like manganese in the clove extract that may substitute calcium ion of hydroxyapatite crystals leading to decrease in the $\mathrm{Ca} / \mathrm{P}$ ratio and forming other crystals 
that may decrease the microhardness of tooth structure. ${ }^{[22]}$ On the contrary to Group1 and Group 2, the microhardness results showed a gradual increase returning to baseline values in the samples treated by MI paste with Cinnamon and Clove extract in Group3, and MI paste alone in Group 4 after treatment. This increase of enamel microhardness in Group3 as well as in Group 4 may be related to the reaction of fluoride ion containing MI paste plus with enamel surface in the form of calcium fluoride which is formed wherever the hard dental tissues are exposed to high concentrations of ionic fluoride. [23, 27] In the current study, MI paste was used as a positive control in Group 4 due to its effective role in remineralization. ${ }^{[28]}$ Using of Cinnamon and Cloves together in group 3 doesn't affect the enamel surface microhardness negatively. This could be explained based on decreasing the amount of both cinnamon and cloves to $0.25 \mathrm{ml}$ each instead to $0.5 \mathrm{ml}$. Also, they may have antagonistic effect when applied together that may be responsible for decreasing their negative effect on enamel microhardness that was previously represented in group 1 and group 2. However, the impact of these herbs on enamel remineralization is less well understood. So that, we recommend that further studies are needed to explain in detail the exact mechanism of interaction between Cinnamon and Cloves and enamel surface remineralization.

Regarding the color analysis, $\Delta \mathrm{E}>3.3$ was considered clinically unacceptable. ${ }^{[29,30]}$ The results of the current study revealed that $\Delta \mathrm{E} 3$ values resulted in the highest mean followed by $\Delta \mathrm{E}$ 2 followed by $\Delta \mathrm{E} 1$. This gradual increase in $\Delta \mathrm{E}$ values from the base line to demineralization and finally the post treatment values representing darker color change. The $\Delta \mathrm{E} 3$ values of groups $1,2 \& 3$ showed color difference $\Delta \mathrm{E} 3>3.3$. This could be attributed to presence of polyphenolic compound (tannin) in both Cinnamon and Clove. The tannin content result in staining of the enamel surfaces especially through the porosities created during the demineralization periods. ${ }^{[31,32]}$ So that the highest
$\Delta \mathrm{E} 3$ value was recorded for the Group 3, that could be attributed to the highest concentration of tannin which was available on the enamel surfaces when both Cinnamon and Cloves added together.

Amazingly, Group 4 (MI paste alone) showed an increased $\Delta \mathrm{E} 3$ (higher than the clinically perceptible value) however, the tendency of the color change was toward the yellow color compared to the reddish tinge in the groups $1,2 \& 3$. And since yellowish is more likely to occur in normal clinical situations, even with aging, the clinical perception of a more yellow tooth is more acceptable than the red one. Therefore, the use of Cinnamon and Clove in anterior zone should not be recommended, while it might be successfully used in the posterior region.

\section{CONCLUSIONS}

Under the limitations of the current study, application of Cinnamon and Clove as herbal antibacterial medicaments does not affect enamel microhardness negatively when added with the MI paste at certain ratio. Meanwhile, unacceptable color changes of enamel surface are expected.

\section{REFERENCE}

1. Hu DY, Hong X, Li X. Oral health in China - trends and challenges. Int J Oral Sci 2011; 3(1): 7-12.

2. Cenci MS, Pereira-Cenci T, Cury JA et al. Relationship between gap size and dentin secondary caries formation assessed in a microcosm biofilm model. Caries Res 2009; 43(2): 97-102.

3. Gold JA. The Role of Chlorhexidine in caries prevention. Oper Dent 2008; 33(6):710-716

4. Palombo, EA. Medical honey for wound care--still the 'latest resort'? Evid Based Complement Alternat Med 2009; 6(2):165-73.

5. Rishton, GM. Natural products as a robust source of new drugs and drug leads: past successes and present day issues. Am J Cardiol 2008; 22; 101(10A):43D-49D.

6. Goyal P, Kaushik P. In vitro evaluation of antibacterial activity of various crude leaf extracts of Indian sacred plant, Ocimum sanctum L.British Microbiology Research Journal 2011;1(3):70-78 
7. Craig WJ. Health-promoting properties of common herbs. Am J Clin Nutr 1999;70 (3):491S-499S.

8. Francis Xavier T, Vijyalakshmi P. Screening of antibiotic resistant inhibitors from Indian traditional medicinal plants against streptococcus mutans. Journal Plant Sci 2007; 2(3): 370-373.

9. Abidin ZZ, Said SM, Abdul Majid FA, MustaphaWA, Jantan I. Anti-Bacterial Activity of Cinnamon Oil on Oral Pathogens. The Open Conference Proceedings Journal, 2013, 4, (Suppl-2, M4) 12-16.

10. Mirpour M, Siahmazg ZG, Kiasaraie MS. Antibacterial activity of clove, gall nut methanolic and ethanolic extracts on Streptococcus mutans PTCC 1683 and Streptococcus salivarius PTCC 1448. $\mathrm{j}$ of oral biology and craniofacial research 2015; 5: 7-10.

11. Featherstone JD. Dental caries, a dynamic disease process. Aust Dent J 2008;53:286-91.

12. Cochrane NJ, Shen P, Yuan Y, Reynolds EC. Ion release from calcium and fluoride containing dental varnishes. Aust Dent J 2014;59:100-5.

13. Cochrane NJ, Cai F, Huq NL, Burrow MF, Reynolds EC. New approaches to enhanced remineralization of tooth enamel. J Dent Res 2010;89:1187-97.

14. Reynolds EC, Cain CJ, Webber FL, Black CL, Riley PF, Johnson IH, et al. Anticariogenicity of calcium phosphate complexes of tryptic casein phosphopeptides in the rat. J Dent Res 1995;74:1272-9.

15. Reynolds EC, Cai F, Shen P, Walker GD. Retention in plaque and remineralization of enamel lesions by various forms of calcium in a mouthrinse or sugar-free chewing gum. J Dent Res 2003;82:206-11.

16. Akman S, Akman M, Eskitascioglu G, Belli S. Influence of several fiber-reinforced composite restoration techniques on cusp movement and fracture strength of molar teeth, Int Endodontic J 2011 ; 44:407-415.

17. Kirsten GA, Takahashi MK, Rached RN, Giannini M, Souza EM. Microhardness of dentin underneath fluoridereleasing adhesive systems subjected to cariogenic challenge and fluoride therapy, J Dent 2010; 48:460-468.

18. Prabhakar AR and Arali V. Comparison of the remineralizing effects of sodium fluoride and bioactive glass using bioerodible gel systems.J Dent. Res. Dent. Clin. Dent. Prospect 2009; 3(4):117-121.

19. Ten Cate JM, Duijsters PP. Alternating demineralization and remineralization of artificial enamel lesions. Caries Research 1982; 16:201-10.
20. Ten Cate JM, Buijs MJ, Damen JJ. pH-cycling of enamel and dentin lesions in the presence of low concentrations of fluoride. European J of Oral Sciences 1995;103:362-7.

21. Sulieman M, Addy M, Rees JS. Development and evaluation of a method in vitro to study the effectiveness of tooth bleaching. J of Dentistry 2003; 31(6):415-22.

22. Al-lami AK, Al-Alousi WS. Effect of water Clove extract on the microhardness and microscopic features of initial caries-like lesion of permanent teeth, compared to fluoridated agent. J Bagh College Dentistry 2011; 23(2) 110-113.

23. Anggono J, Damiyanti $M$ and Eriwati $Y$ K. Effect of cinnamon extract solution on tooth enamel color .2018 J. Phys. Conf. Ser. 1073032025

24. Jadhav B. K, Khandelwal KR, Ketkar AR, and Pisal SS. Formulation and evaluation of mucoadhesive tablets containing eugenol for the treatment of periodontal disease. Drug Development and Industrial Pharmacy 2004; 30, 2,195-203.

25. Fani M M and Kohanteb J 2011 Inhibitory Activity of Cinnamon zeylanicum and Eucalyptus globulus Oils on Streptococcus mutans, Staphylococcus aureus and Candida Species Isolated from Patients with Oral Infections. Shiraz Univ Dent J 2011; Vol.11, (Supplement) 14-22.

26. Ensminger A, Esminger M. Food for Health. A Nutrition Encyclopedia. Clovis, California: Pegus Press 1986.

27. Exstrand J, Whitford GM. (1988): Fluoride Metabolism. In: Fluoride In Dentistry, J. Ekstrand, O. Fejerskov, and L.M. Silverstone, Eds., Copenhagen: Munksgaard, pp. 150-170

28. Einsphar H, Bugg C. Enamel appatite and caries. In the biological bases of dental caries. Harper and Row publ Hagerstown 1980; 191- 207.

29. Inokoshi S, Burrow MF, Kataumi M, YamadaT, Takastu T: Opacity and color changes of tooth colored restorative materials. Oper- ative Dent 1996; 21(2):73-80.

30. Janda R, Rouet JF, Lata M, Kaminsky M. Effect of exponential polymerization on color stability of resin based filling materials. Dent Mater J 2007; 23: 696-704.

31. Nordbo H. Discoloration of dental pellicle by tannic acid. Acta. Odontol. Scand. 1977; 35, 305

32. Yu H, Oho T, Xu X. Effects of several tea components on acid resistance of human tooth enamel. Department of Preventive Dentistry, Kyushu University, Fukuoka, Japan. J Den 1995; 101-5. 